\title{
REFLECTIONS ON COMPANION ANIMALS
}

\author{
JOHN F. KULLBERG \\ American Society for the Prevention \\ of Cruelty to Animals
}

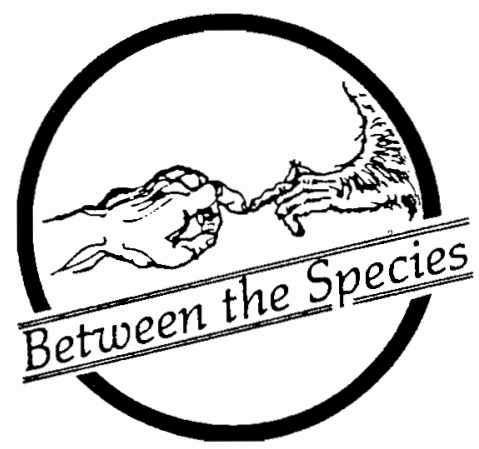

Editor's Note: The following is the text of an address made by Dr. Kullberg, ASPCA President, to the New York State Humane Association Conference on Pet Overpopulation, September 12, 1987.

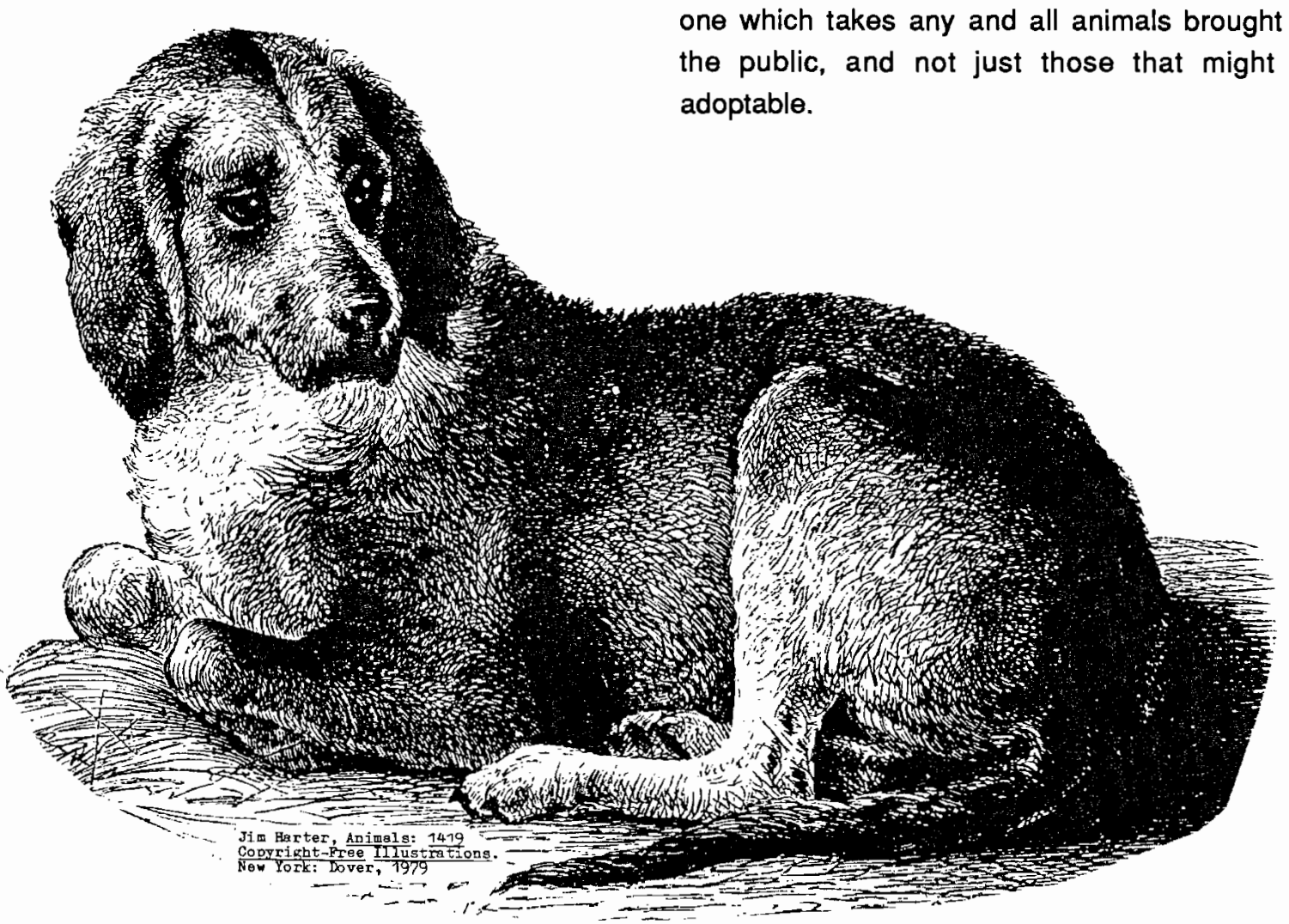

I have been asked to address the topic of animal shelter responsibilities, and 1 have chosen to focus my comments on the animal shelter's role in education and legislation.
Given the volume of animals that many shelters receive---the ASPCA, for example, received some 80,000 unwanted or lost animals in its two New York City shelters last year---it might be useful first to consider the sources of animals brought to ASPCA-type animal shelters and the assortment of animals received. For the purpose of this discussion I am defining an ASPCA-type animal shelter as one which takes any and all animals brought by the public, and not just those that might be adoptable.

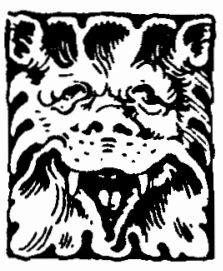

\section{ACTIVISM/ COMMENT}


In addition to unwanted owned or lost or abandoned stray animals, shelters also receive animals seized during investigations conducted by law enforcement authorities. At the ASPCA these authorities also include our own peace officers. Some of these animals are taken from abandoned buildings, others during law enforcement raids on sites where animals are used for criminal purposes (e. g., cockfighting, dogfighting, and animal sacrifice rituals). Other animals are rescued from fires or evictions or are held while their owners are

jailed or seriously ill. ASPCA-type shelters also typically have an ambulance rescue division. The ASPCA, for example, retrieved some 30,000 straying and/or injured animals from New York City streets, parks, abandoned buildings and private residences in 1986 .

Given the variety of sources of animals coming to an animal shelter, the shelter must be prepared to care appropriately for these animals. When an animal shelter is not equipped or, for whatever other reason, cannot care for certain types of exotic animals, it needs to establish liaisons with others in surrounding communities who can.

The assortment within the 80,000 animals received by the ASPCA's two New York City shelters in 1986 included, of course, cats and dogs but also a variety of wild as well as domesticated birds, horses, ferrets, gerbils, hamsters, white mice and other rodents, rabbits, skunks deskunked, raccoons, lizards, boa constrictors and other snakes, and tarantulas, and this list is far from complete. Were we to add in the other 50,000 New York City animals cared for in ASPCA veterinary hospitals and spay/neuter clinics and at the ASPCA's J. F.Kennedy airport shelter the list of animal species would be greater still. The 130,000 animals that the ASPCA directly cared for in New York City in 1986, by the way, was the greatest volume of animals directly cared for by any humane society or government agency in America, and that includes the animal control program run by the City of Los Angeles. But if all that a shelter did was to care for animals brought to it and recirculate as many of these animals as possible through responsible adoption programs, the shelter would be doing little or nothing to ameliorate the problems that bring so many unwanted animals to shelters in the first place. What the shelter must do, in addition, is to educate the community on the

causes of the dilemmas the shelter daily faces in coping with its quantities of a wide variety of unwanted animals and, working with various community sources for change, do everything it can to set in motion legislative and other activities that could expeditiously attack the causes of the pet overpopulation problems: greed, indifference, and other assorted wasteful and inhumane attitudes of a materialistic, self-centered and selfish society.

Our biggest problem is the inherent American attitude that treats animals like materialistic commodities. By what right do we incorporate the lives of companion animals into our own? "I've been had" is for us a perjorative term. But that's what most companion animals would say if they could speak. Some here today would insist that having companion animals is ethically wrong, a remnant of slavery. For example, we masters own others, demand obedience, even shackle our commodities at times, and give rewards based on good behavior. Bad behavior often leads to beatings, dismissal, and even extermination. Ethical values are not wellserved unless stewardship, not ownership, is the norm for companion animal care.

In large part because of an all too permeating "domination" attitude in our society, the need for shelters, spay/neuter clinics, and, yes, sodium pentobarbital solution continues to escalate while free enterprise thrives on ever-increasing market demand for puppy mill products, pet foods and such $x$ rated products as the controversial flea and tick repellent, Blockade. Shelters, spaying and neutering clinics, humane law enforcement and human educational antidotes are not adequately 
present today to diminish this societal thirst for more and more pet products and more and more pets.

Sharing our lives with companion animals must be seen as a privilege, not a right, and a privilege that should be tightly, ethically regulated according to what's good for these animals, not what a human argues might be good for humans.

Given an overall commitment on the part of shelter workers and volunteers to more ethical standards for having and then caring for companion as well as other animals, some immediate remedial action can then be initiated.

For starters, shelters must participate in, and lead, efforts to convince legislators to regulate companion animal breeding by individuals (i. e., back yard, miracle of life breeders, professional breeders and puppy mill owners). Breeding must be severely discouraged and spaying and neutering highly rewarded. A $\$ 50$ dog license spay/neuter differential is not too high, and neither is a $\$ 100$ breeding permit for individuals, and $\$ 1,000$ or more for professionals, with permits available only when the applicant can demonstrate that the intended pups or kittens can and will be placed with responsible, caring individuals and families. And we must have heavy fines applied for noncompliance with dog license and breeding permit legislation. The day has come when we must recognize that pet breeding, except in exceptional circumstances, is to be seriously discouraged.

We must also discourage pet store dealers and other breed entrepreneurs in other ways from continuing in business, particularly those pet entrepreneurs who ply their trade in areas where shelters and pounds cannot find responsible homes for unwanted pets. Across the nation these shelters kill more than 35,000 dogs and cats every day, many of whom are perfectly healthy and of excellent disposition. These animals are killed because shelter workers and volunteers cannot find responsible homes for them and because shelter cages and dog runs are constantly overflowing from the steady stream at the intake counter of more and more unwanted animals. Estimates range as high as 15 million unwanted dogs and cats killed in the United States every year and, still, the dog and cat breeders breed and breed and get richer and richer. Shelter managers might well consider asking volunteers to leaflet those who trade at pet shops, letting these potential pet shop customers know that hundreds of perfectly healthy and welldispositioned animals are waiting in nearby shelters for good, responsible homes. The pet stores work off supply and demand. The shelters do not. At shelters, the supply is rising and there is no commensurate demand. Let's stop public dependence on pet shops and pet breeders while shelters are forced to kill healthy animals. We don't have human baby shops. Let's stop having puppy and kitten shops.

Those who work in shelters must also fight the researchers who look upon the tragedy of pet overpopulation and the consequent shelter and pound populations of unwanted animals as research laboratory resources. On the federal legislative level we need to become personally involved in lobbying for passage of New York State Congressman Mrazek's federal bill, the Pet Protection Act (H. R. 778). But don't be lulled into a false sense of achievement even if this much-needed federal legislation is finally passed. The Mrazek bill will not replace the need for state legislation prohibiting pound and shelter animal seizure in those states currently without such legislation. The proposed federal law only applies to prohibiting the use of pound and shelter animals in research where the funding source is the $U$. S. government. State grass roots efforts to ban pound seizure are essential, with support from humane societies and using the resources developed and available through the National Coalition to Protect Our Pets, if the disgrace of pound seizure is to be, once and for all, ended. 
The pet food industry in the United States currently grosses more that $\$ 7$ billion a year. Add in the gross of the pet supply industry and this figure approaches $\$ 10$ billion annually. A $5 \%$ wholesale tax to fund programs attacking the causes of pet overpopulation could bring hundreds of million of dollars each year to community animal shelter and spay/neuter clinic needs, humane law enforcement efforts and human education media-based tutorials that focus not on kindness but on responsibility, stewardship and obligation. Those who operate or who would like to operate shelters and spay/neuter clinics should be leading the fight for this desperately needed tax. The reason free spay/neuter clinics are not all over

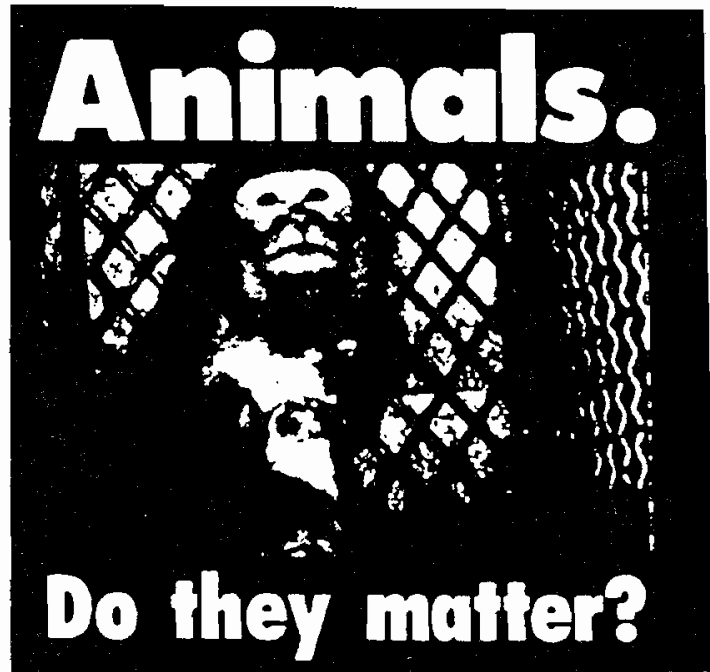

The animal rights movement is as diverse as the animals it seeks to prorect and only one publication. The ANIMALS AGENDA gives you com. prehensive coverage of its successes. is probiems. its people. and its organizations

10 issues per yr. -65 pgs. and growing!t

YES, send me The ANIMALS' AGENDA.

$\square 1$ yr. $\$ 18.00 \square 2$ yrs. $\$ 3350 \square 3$ yrs. $\$ 45.00$

$\square$ Payment enclosed $\square$ Bill me

Name

Street

City State Zip

The ANIMALS' AGENDA Subscriptions P.O. Box 6809, Syracuse, NY 13217
Boston, New York and Chicago, for example, is the the politicians claim that they have no money for them. Let's help politicians find the money! I submit that the quickest route to the kinds of money needed is a tax that would raise the price of a can of cat food by less than 2 cents. The pet food producers, in part responsible through their marketing efforts for companion animal overpopulation and related problems, should pay a generous share of the costs for long overdue and increasingly needed solutions. They will not do so in anywhere near an adequate way voluntarily. They should therefore be forced to help us through a dedicated tax.

Finally, shelters must work to counter some of the negative side of the human/animal companion bond studies. Reducing animals to vitamin pills is a very dangerous precedent. If human/animal companion bond studies promote respensible care of animals (even if only because pet benefits to human health make pets "worth" more), fine. But if the studies promote the notion that everyone should have a companion animal whether or not he or she can care for a pet responsibly, then we have even more serious problems ahead of us.

Valuing animals on the basis of what they can do for us is the same as our valuing each other on the basis of what we can do for each other. That standard violates inherent worth, and it is wrong. We deserve more, and so do companion animals. Those who operate shelters must dedicate themselves to educational and legislative tasks that are aimed at the causes as well as the results of pet overpopulation if we are to make significant and long-lasting gains in overcoming society's pernicious, inhumane attitudes toward animals generally and pets particularly. 


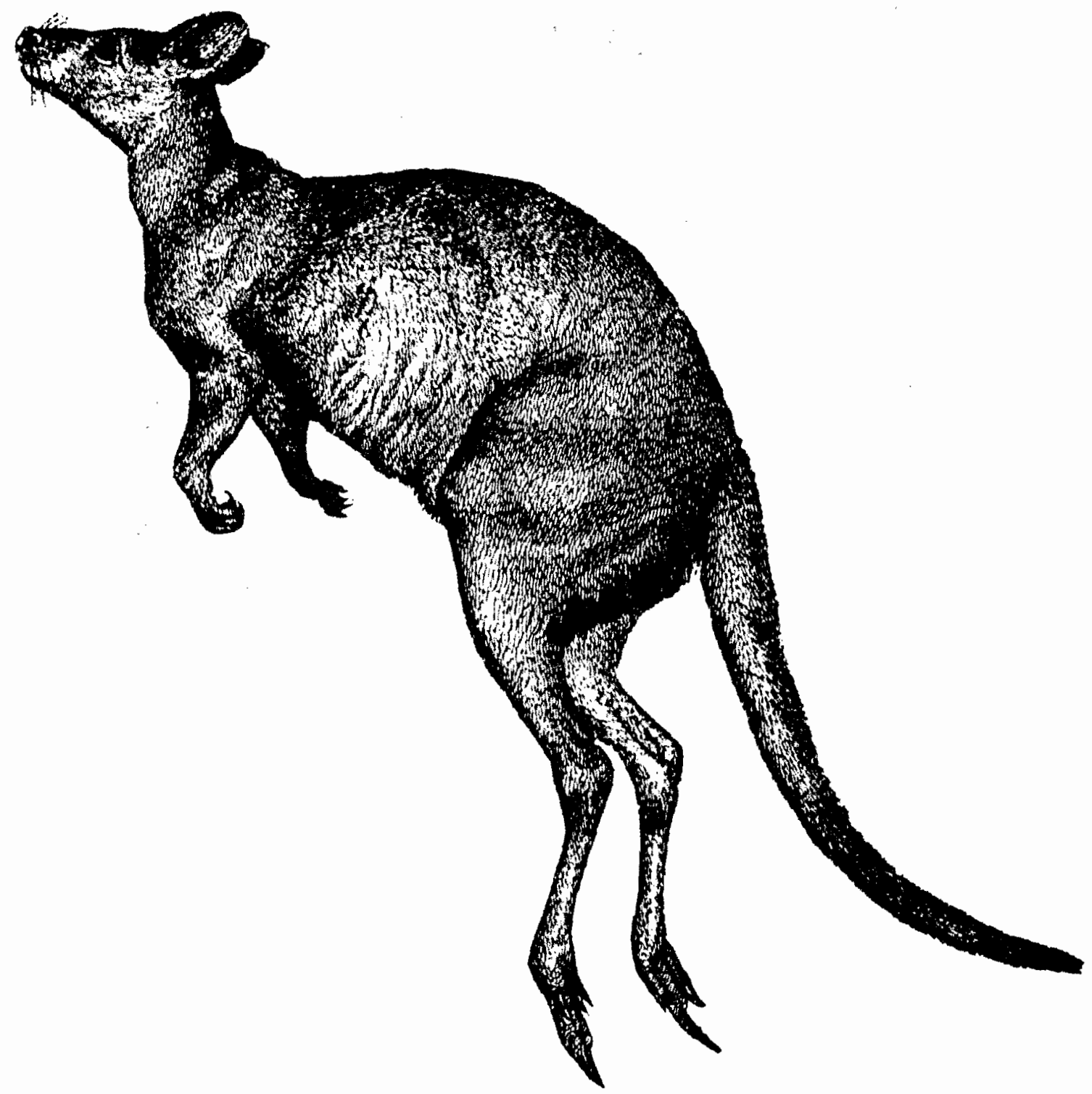

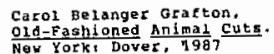

